\title{
Global Echoes
}

BJPsych International would like to encourage submissions from medical students, foundation doctors and psychiatry trainees. Those who are beginning their careers in mental health are often involved in high-quality projects or have diverse training and clinical backgrounds that would be stimulating for our readers to discover. They represent a valuable source of knowledge that can help all professionals to keep abreast of what is happening in the field around the world. We would like to receive submissions in the following areas, with a focus on international mental health work: brief literature reviews on mental health policy or services; reports of elective projects in psychiatry or other experiences of working or volunteering abroad; reflective or descriptive pieces about work undertaken or experiences or challenges encountered in working around the world, or in carrying out research in challenging contexts. Submissions should be between 500 and 1500 words and original pieces. Email ip@rcpsych.ac.uk. Submissions will undergo peer review. See the online BJPsych International guidelines on format and style (https://www.cambridge.org/core/journals/ bjpsych-international/information/instructionscontributors).

\section{International Perspectives on Psychiatry Under Restrictive Conditions}

$B$ JPsych International is seeking to survey across the world the practice of psychiatry in restrictive settings and conditions (prisons, jails, on parole, conditional release and community treatment under legal provision) as well as coercive practices in the management of people with a mental illness, beyond psychiatry. The journal, therefore, is inviting authors to submit papers on national or regional aspects of one or more of the above areas, highlighting current practice, relevant data (or lack of the same), training and service needs and areas for future research.

For further information, please contact the deputy editor, George Ikkos, at ikkos@doctors. org.uk 


\section{BJPsych}
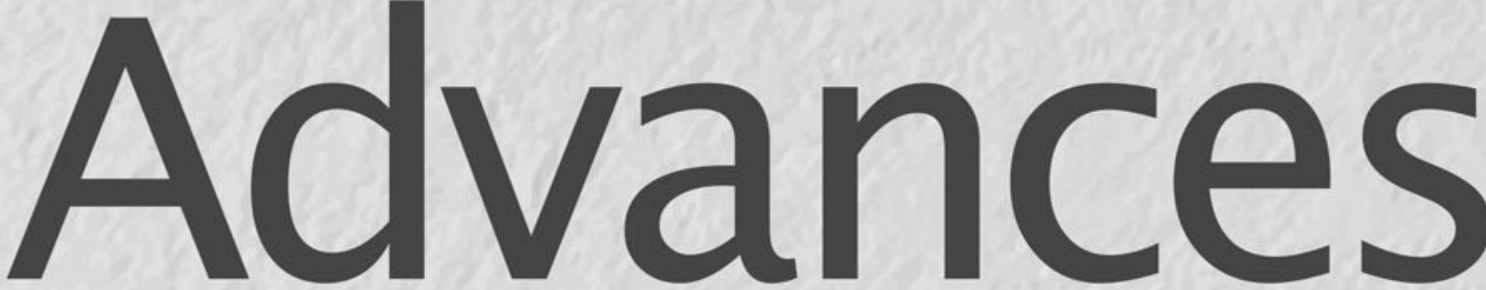

Continuing professional development in psychiatry

\section{Call for Article Proposals}

BJPsych Advances, RCPsych's peer-reviewed CPD journal for consultant psychiatrists, invites clinical experts to submit proposals for articles on current ideas, techniques and developments in psychiatry. Articles typically discuss comprehensive, practical approaches to clinical problems and explain the full range of therapeutic options, with useful features like MCQs, summary boxes, and associated commentaries.

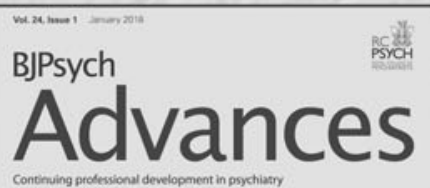

To submit a proposal to the journal, please email:

apt@rcpsych.ac.uk

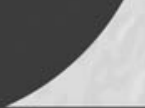

For further information visit: cambridge.org/bjpsych-advances 


\section{Special Papers}

49 Maudsley International: improving mental health and well-being around the world

Nick Bouras, Silvia Davey, Tracey Power, Jonathan Rolfe, Tom Craig and Graham Thornicroft

\section{Editorial}

51 Public mental health: key challenges and opportunities Jonathan Campion

54 A call for more evidence-based practice

David Skuse

\section{Thematic Papers}

55 Evidence-based practice in a multicultural world: changing with the times

Claire Tiley and Marinos

Kyriakopoulos
58 Evidence-based practice in Chile Constanza Caneo and Jorge Calderón

61 Advances in the treatment of substance use disorder in Cyprus Lampros Samartzis

\section{Mental Health Law Profiles}

63 Mental health law in the Former Yugoslav Republic of Macedonia Antoni Novotni, Nensi Manusheva and Gabriela Novotni

\section{Editorial}

65 The mental health of asylum seekers in Australia and the role of psychiatrists

Derrick Silove and Sarah Mares

\section{Pandora's box}

Eleni Palazidou
BJPsych International

(Print)

ISSN 2056-4740

BJPsych International (Online)

ISSN 2058-6264

Pressure of Evidence, 2016, alkyd on panel, by Will Lustenader, Courtesy of the Fred. Giampietro Gallery

Will Lustenader is a professional artist and adjunct professor of art history based at Sacred Heart University, Albertus Magnus College, and Gateway Community College. In his work, he puts emphasis on tension in and around planar colour fields whose arrangements present questions concerning territorial environments, both physical and imagined. As his pieces unfold, often with long periods of reflection between groups of work, he finds himself contemplating immersion and entrapment. Recently his impulsive, spontaneous rhythm of creation has led him to a preoccupation regarding balance and containment, and ultimately has freed him from the pressures of being fixed to a plan. 